\title{
Testostérone circulante et cancer de la prostate. Revue de données récentes
}

\author{
Pär STATTIN \\ Dept of Urology and Andrology, Umeå University Hospital, Umeå, Sweden
}

\section{RESUME}

Des études in vitro et in vivo ont monté que les androgènes stimulent le cancer de la prostate. Cependant les études épidémiologiques n'ont pas mis clairement en évidence d'association entre les niveaux circulants d'androgènes et le risque de cancer de la prostate. Toutefois la plupart des études n'avaient pas la taille requise pour mettre en évidence un lien qui peut être relativement faible.

Les études prospectives de l'association entre la concentration sérique de testostérone libre et totale, le principal androgène circulant, et le risque de cancer de la prostate ont été revues.

Il n'a pas été mis en évidence d'association significative entre la testostérone libre ou la testostérone totale et le risque de cancer de la prostate dans des études qui totalisent 1525 cas de cancer de la prostate et 4349 sujets témoins. Il n'y a pas d'argument pour défendre l'hypothèse selon laquelle, des concentrations élevées de testostérone dans la gamme physiologique, stimulent le développement et la croissance du cancer de la prostate. Le métabolisme intraprostatique des androgènes peut néanmoins être important pour le développement du cancer de la prostate.
Mots Clés : cancer de la prostate, androgènes, testostérone, épidémiologie, études prospectives

\section{INTRODUCTION}

L'hypothèse selon laquelle les androgènes jouent un rôle dans la pathogénie du cancer de la prostate chez l'homme est principalement basée sur des arguments tirés d'études de modèles tumoraux [4]. In vitro, une réponse aux androgènes est observée dans la plupart des lignées cellulaires tumorales prostatiques bien différenciées $[18,35]$ et in vivo, les androgènes stimulent clairement l'induction et la promotion de tumeurs prostatiques et de xénogreffes de tumeurs prostatiques chez les rongeurs alors que la suppression des androgènes entraîne une régression tumorale $[19,3]$.

Dans l'espèce humaine, une augmentation du risque de cancer de la prostate peut être due à une production testiculaire de testostérone élevée donnant des concentrations élevées de testostérone dans la circulation et/ou à des altérations tissulaires de la prostate augmentant la stimulation androgénique dans la prostate [4]. Comme l'indiquent des revues récentes $[7,17,15]$, au moins une dizaine d'études de taille modeste ont recherché une relation en faveur de la première hypothèse, c'est-à-dire une association entre les concentrations circulantes d'androgènes et le risque de cancer de la prostate. Globalement, les résultats de ces études n'ont pas permis de conclure, certaines études ont montré une augmentation modérée du risque $[14,8,13,12]$, alors que d'autres ont trouvé une diminution modérée du risque $[31,6]$, mais aucune de ces études n'a montré une association statistiquement significative entre la concentration circulante absolue de testostérone, le principal androgène de la circulation et le risque de cancer de la prostate.

Correspondance :

Pär STATTIN - Dept of Urology and Andrology, Umeå University Hospital, 90185 Umeå, Sweden -

$\mathrm{Tel}+46-907851331$ - Fax +46-90125396 -

Email par.stattin@urologi.umu.se 
On considère que la forme la plus représentative de la testostérone biologiquement active est la testostérone biodisponible ou la testostérone libre. La testostérone biodisponible est la fraction de la testostérone non liée à la sex hormone binding globulin (SHBG), la principale protéine de liaison de la testostérone circulante, et la testostérone libre est la testostérone qui n'est lié à aucune protéine. Comme la concentration d'albumine est identique entre les individus, les résultats des deux méthodes de dosage sont hautement corrélés. Quelques études ont étudié l'association entre la testostérone libre sérique et le risque de cancer de la prostate. Aucune association significative n'a été observée dans les trois études ayant mesuré la testostérone libre par méthode directe $[12,6,25]$.

Les concentrations circulantes de testostérone sont inversement corrélées à l'obésité qui a été inconstamment associée avec un risque légèrement augmenté de cancer de la prostate $[17,2,5]$.

Cet article présente une brève revue des deux études les plus importantes $[7,27]$ recherchant une association entre la testostérone totale et la testostérone libre et le risque de cancer de la prostate, prenant aussi en compte l'obésité.

\section{POPULATIONS ÉTUDIÉES ET RÉSULTATS}

La publication d'Eaton et collaborateurs est une méta-analyse de 8 études prospectives publiée avant 1999 et incluant 817 cas et 2107 sujets témoins ayant eu un dosage de testostérone totale [7]. Notre étude est une analyse de 708 cas et 2242 sujets témoins issus de trois banques biologiques nordiques: The Janus Serum Bank d'Oslo, Norvège, The Helsinki Heart Study d'Helsinki, Finlande, et the Northern Sweden Health and Disease Cohort d'Umeá, Suède [27]. Le nombre de cas est de 537 pour la Norvège, 84 pour la Finlande et 87 pour la Suède. Pour chaque pays, 4 sujets témoins ont été appariés pour l'âge et la date de prélèvement sanguin à chaque cas de cancer de la prostate.

Dans notre publication [27], il existe une corrélation directe entre la testostérone totale et la testostérone libre $(r=0,78)$, ainsi qu'entre la testostérone totale et la SHBG $(r=0,51)$, par contre la corrélation entre la SHBG et la testostérone libre est très faible $(r=-0,08)$. Dans cette même publication, l'index de masse corporel est inversement corrélé à la SHBG $(r=-0,33)$ et à la testostérone totale $(r=-0,28)$, et moins fortement à la testostérone libre $(r=-0,14)$ (Figure 1).

\section{Risque de cancer de la prostate et concentrations de} testostérone totale et libre.

Dans la méta-analyse de Eaton et coll. [7], il n'y a pas d'association significative entre les concentrations de testostérone totale et le risque de cancer de la prostate lorsque l'on analyse l'ensemble des cas et des témoins (Figure 2). On trouve des résultats similaires sur l'ensemble des études nordiques (Figure 3). Pour la testostérone libre, la métaanalyse et l'ensemble des études nordiques donnent les mêmes résultats, il n'y a pas d'association significative entre les concentrations de testostérone libre et le risque de cancer de la prostate (Figures $4 a$ et $4 b$; Figures $5 a$ et $5 b$ ). Les estimations du risque restent inchangées dans l'étude des populations nordiques si l'analyse est ajustée à l'index de masse corporelle. De même, l'estimation du risque reste globalement similaire si l'analyse est réalisée en sous-groupe en fonction de l'âge et du délai de survenue.

\section{DISCUSSION}

Dans ces deux études, une méta-analyse [7] et une étude sur trois bases de données nordiques [27], l'ensemble représentant 1525 cas de cancer de prostate, il n'a pas été trouvé d'association entre la testostérone totale ou la testostérone libre et le risque de cancer de la prostate.

En ce qui concerne le niveau d'exposition aux androgènes, dans les deux études, on constate une différence de testostérone totale de deux fois environ entre les individus ayant les valeurs maximales d'androgènes et ceux ayant les valeurs minimales. Lorsque l'administration d'androgène induit une telle différence dans des modèles tumoraux des rongeurs, il se produit une augmentation substantielle de l'induction et de la promotion des tumeurs de prostate [4]. Toutefois une administration à court terme d'androgènes dans des modèles murins peut ne pas être équivalent à une exposition chronique à des niveaux modérément élevés d'androgènes chez l'homme.

La plupart des stéroïdes sexuels se conservent assez bien dans les échantillons congelés, même sur de longues durées $[28,23]$; néanmoins un certain degré de dégradation ne peut pas être exclu pour ces études dans lesquelles certains échantillons ont été conservés pendant de très longues durées. Toutefois comme les cas et les témoins ont été appariés pour la date du prélèvement sanguin, la dégradation ne doit pas avoir affecté de manière différente les échantillons des cas et des témoins et ne pourrait qu'avoir tendance à atténuer l'association au risque. Les concentrations de testostérone sont relativement constantes au cours du temps chez un même individu. Des coefficients corrélation de 0,7 à 0,9 ont été rapportés, entre les concentrations d'échantillons prélevés à environ trois ans d'écart $[23,9,33$, 30]. On ne sait toutefois pas si un prélèvement sanguin unique est représentatif pour des périodes plus longues.

La concentration de testostérone libre, forme biologiquement la plus directement active de la testostérone, est mesurée au mieux par dialyse à l'équilibre. Cette méthode n'a pas été fréquemment utilisée dans les études épidémiologiques en raison de l'important volume d'échantillon nécessaire et du temps de réalisation de la méthode. II a été montré que l'indice de testostérone libre calculé à partir de la testostérone totale et de la concentration de la SHBG, comme utilisé dans les études épidémiologiques que nous décrivons ici, est en bonne corrélation avec la mesure directe de la testostérone libre par dialyse [23, 1, 34].

La testostérone totale ajustée linéairement à la SHBG peut aussi être utilisée comme un index calculé de la testostérone biologiquement active. Une publication de Gann et al. [8], souvent citée, rapporte une augmentation significative 

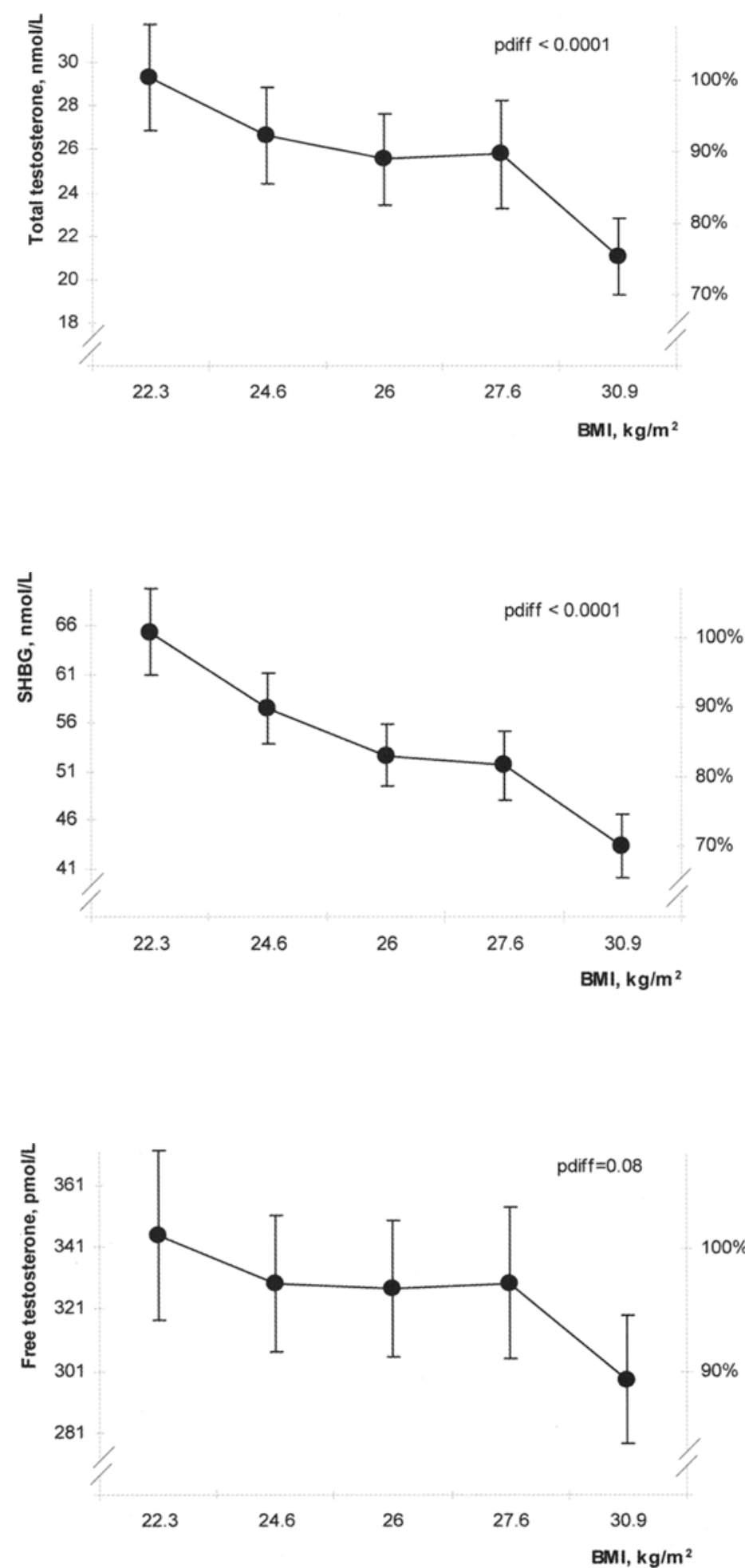

Figure 1 : Concentrations moyennes de testostérone totale, SHBG et testostérone libre en fonction des quintiles de l'index de masse corporelle (body mass index : BMI) dans l'étude nordique [27].
Testosterone

$\begin{array}{llllll}\text { First author } & \text { Year } & \text { Cases/controls } & \text { ratio } & 95 \% \mathrm{Cl} & \text { Ratio and } 95 \% \mathrm{Cl} \\ \text { Barrett-Connor } & 1990 & 59 / 945 & 0.95 & (0.85-1.06) \\ \text { Hsing } & 1993 & 98 / 98 & 1.02 & (0.89-1.17) \\ \text { Carter } & 1995 & 16 / 16 & 0.83 & (0.62-1.11) \\ \text { Gann } & 1996 & 222 / 390 & 1.02 & (0.94-1.10) \\ \text { Nomura } & 1996 & 141 / 141 & 1.00 & (0.91-1.10) \\ \text { Guess } & 1997 & 106 / 106 & 0.99 & (0.90-1.09) \\ \text { Vatten } & 1997 & 59 / 180 & 0.97 & (0.88-1.07) \\ \text { Dorgan } & 1998 & 116 / 231 & 0.98 & (0.91-1.06) \\ \text { All studies } & & 817 / 2107 & 0.99 & (0.95-1.02) \\ \text { Test for heterogeneity } \chi_{7}^{2}=0.3 ; P>0.1, N S & 0.6 & 0.8\end{array}$

Figure 2 : Méta-analyse des études prospectives de l'association entre les concentrations de testostérone totale et le risque de cancer de la prostate [6].

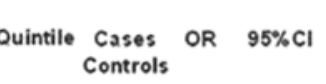

All countries $\quad$ Controls

$\begin{array}{lll}144 / 441 & 1.00 & \text { referent } \\ 148 / 435 & 1.02 & 0.78-1.34\end{array}$ $\begin{array}{lll}148 / 435 & 1.02 & 0.78-1.34 \\ 166 / 426 & 1.15 & 0.88-1.50\end{array}$ $\begin{array}{lllll}123 / 458 & 0.81 & 0.61-1.08\end{array}$ $\begin{array}{lll}123 / 470 & 0.80 & 0.59-1.06\end{array}$

Norway

Sweden

Finland and Sweden

$110 / 3151.00$ referent

$114 / 311 \quad 1.03 \quad 0.76-1.41$

$\begin{array}{llll}120 / 308 & 1.07 & 0.78-1.45\end{array}$

$\begin{array}{llll}102 / 323 & 0.89 & 0.64-1.22\end{array}$

$88 / 342 \quad 0.71 \quad 0.51-1.00$

$34 / 126 \quad 1.00$ referent

$34 / 124 \quad 1.01 \quad 0.59-1.73$

$\begin{array}{llll}45 / 116 & 1.45 & 0.86 \cdot 2.44\end{array}$

$\begin{array}{llll}25 / 138 & 0.71 & 0.39-1.28\end{array}$

$32 / 127 \quad 1.01 \quad 0.56-1.81$

Finland

16/58 100 referent

$\begin{array}{lll}15 / 60 & 1.00 & 0.45-2.24\end{array}$

$\begin{array}{llll}16 / 58 & 1.04 & 0.47-2.27\end{array}$

$22 / 54 \quad 1.58 \quad 0.72 .3 .43$

$\begin{array}{llll}15 / 61 & 1.03 & 0.46-2.28\end{array}$

17/67 1.00 referent

$\begin{array}{llll}23 / 63 & 138 & 0.67-2.86\end{array}$

$\begin{array}{llll}16 / 69 & 0.89 & 0.40-1.97\end{array}$

$\begin{array}{llll}15 / 70 & 0.84 & 0.38-1.86\end{array}$

$\begin{array}{llll}15 / 71 & 0.82 & 0.37 .1 .81\end{array}$

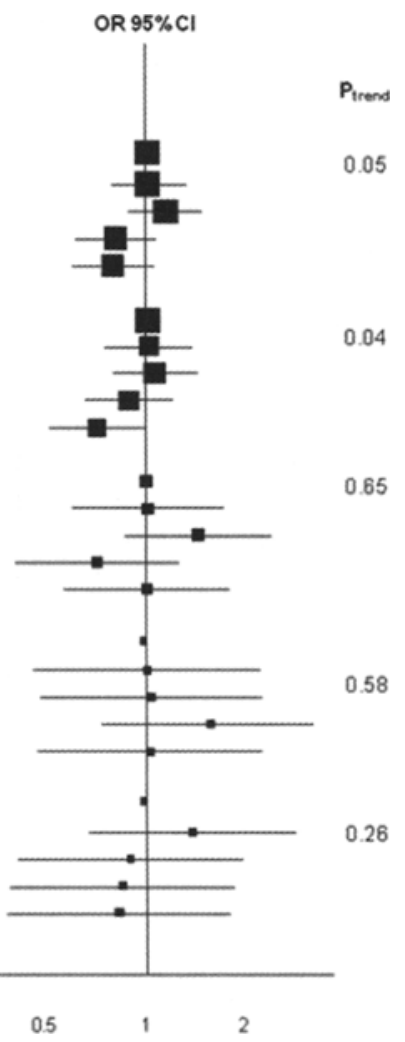

Figure 3 : Odds ratios du cancer de la prostate en fonction des quintiles de la concentration de testostérone totale dans l'étude nordique [27]. 
Sex hormone binding globulin

First author Year Cases/controls ratio $95 \% \mathrm{Cl} \quad$ Ratio and $95 \% \mathrm{Cl}$

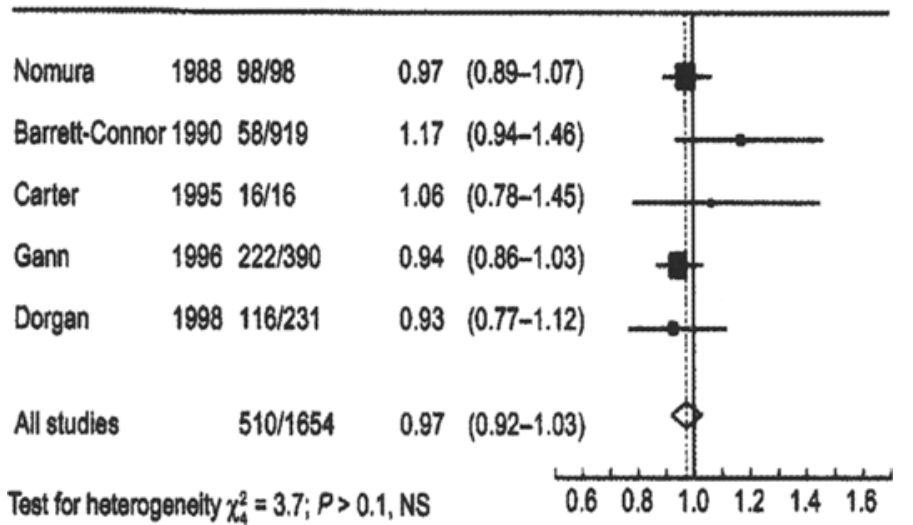

Test for heterogeneily $\chi_{4}^{2}=3.7 ; p>0.1$, NS

$\begin{array}{llllll}0.6 & 0.8 & 1.0 & 1.2 & 1.4 & 1.6\end{array}$
Non-SHBG bound testosterone

First author Year Cases/controls ratio $95 \% \mathrm{Cl}$

Ratio and $95 \% \mathrm{Cl}$

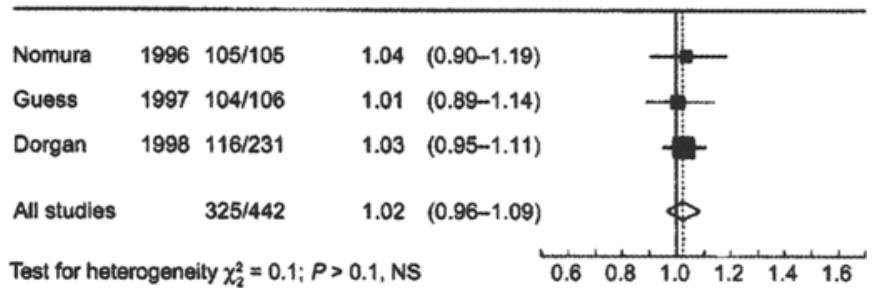

Figure 4a : Méta-analyse des études prospectives de l'association entre les concentrations de SHBG et le risque de cancer de la prostate [6].
Figure 4b: Méta-analyse des études prospectives de l'association entre les concentrations de testostérone non liée à la SHBG et le risque de cancer de la prostate [6].

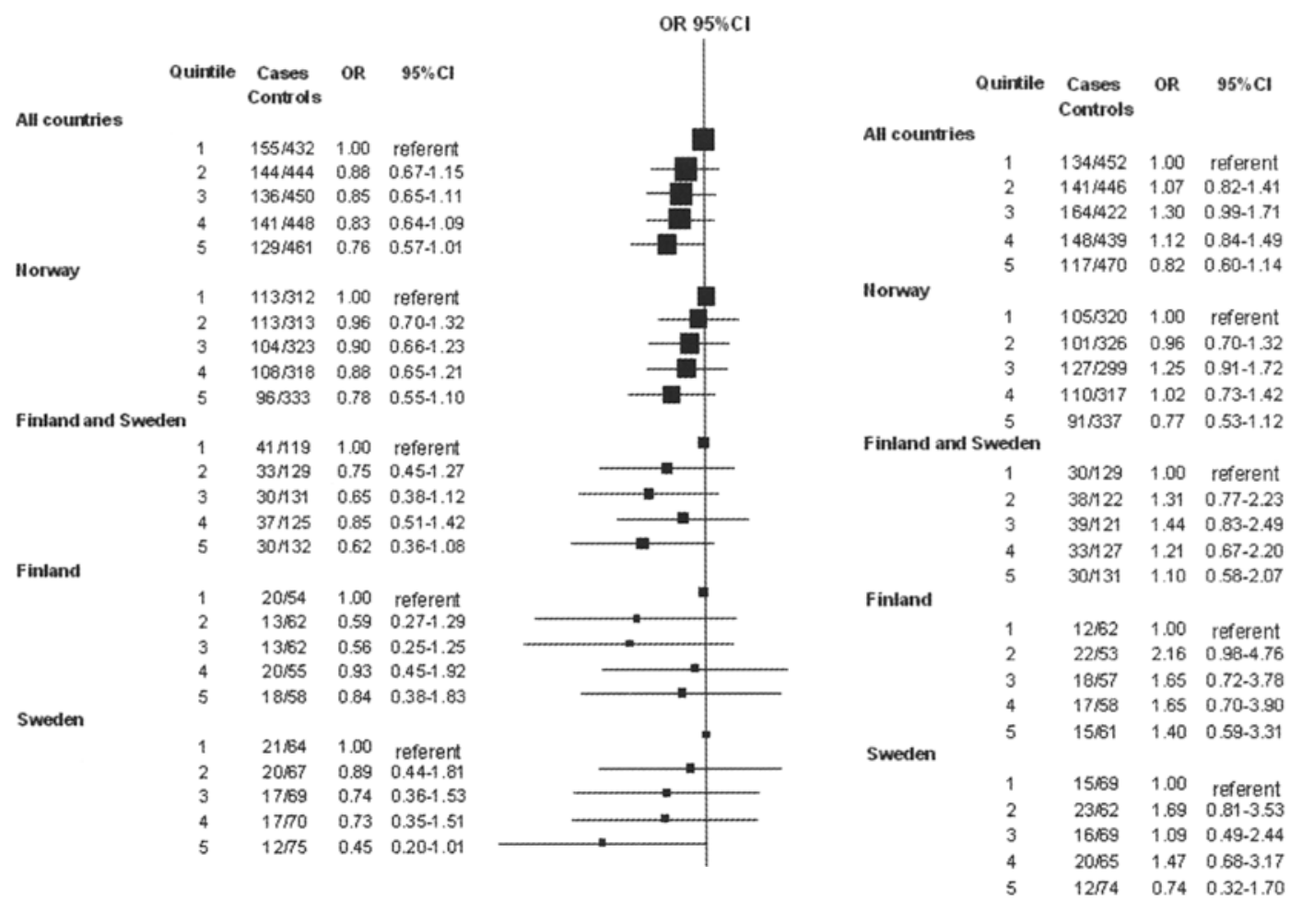

Figure 5a: Odds ratios du cancer de la prostate en fonction des quintiles de la concentration de SHBG dans l'étude nordique [27].

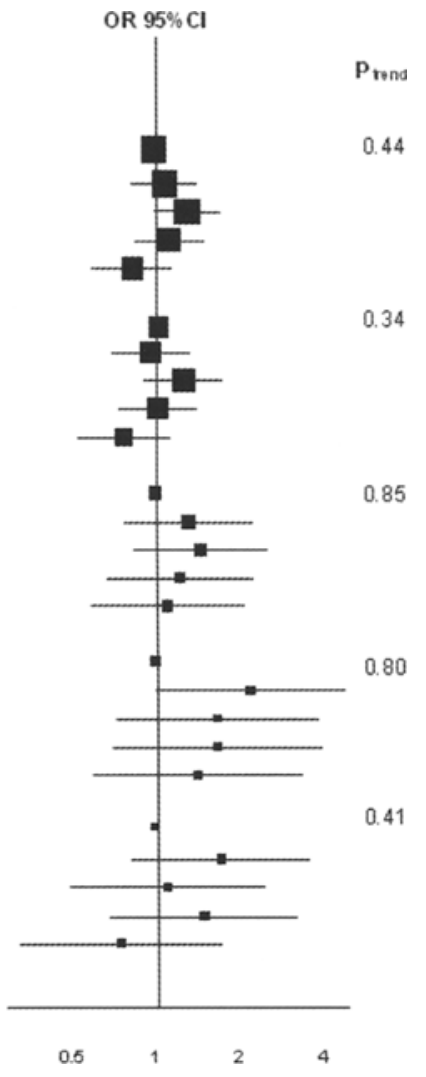

Figure 5b. : Odds Ratios du cancer de la prostate en fonction des quintiles de la concentration de testostérone libre dans l'étude nordique [27]. 
du risque de cancer de la prostate en fonction de la testostérone totale linéairement ajustée à la SHBG, dans la Physician's Health Study [8]. À l'opposé, dans notre étude des bases de données nordiques [27], une diminution non significative du risque est trouvée pour la testostérone après l'ajustement à la SHBG comme réalisés par Gann et al. [8]. Dans cette même étude, le risque décrit un profil en cloche, avec une légère augmentation pour des niveaux intermédiaires et une diminution pour les concentrations les plus hautes de testostérone libre calculée à partir de la testostérone totale et de la SHBG.

Un argument indirect en faveur de l'hypothèse que de hauts niveaux d'androgènes circulants représentent un facteur de risque de cancer de la prostate provient de la régression importante de la symptomatologie tumorale chez une majorité d'hommes ayant des cancers de la prostate avancés lors de la suppression androgénique qui comporte un arrêt total de la production testostérone par le testicule [24]. Toutefois, cet effet drastique de la réduction des niveaux d'androgènes observé à un stade très tardif du développement du cancer n'est pas un argument suffisamment probant en faveur de l'effet de variations dans la gamme des valeurs physiologiques d'androgènes sur des événements tumorigènes précoces qui se produisent des dizaines d'années auparavant.

Bien que parfois inconsistante, une association directe modérée entre l'obésité, mesurée par le BMI, et le risque de cancer de la prostate a été trouvée dans la plupart des études prospectives $[17,2,5]$. Dans l'analyse compilée des bases de données nordiques, on trouve une assez forte corrélation négative entre le BMl, la SHBG et la testostérone totale mais moins forte avec la testostérone libre, ce qui est en bon accord avec le fait que la diminution de la concentration de la SHBG, induite par l'obésité, fait diminuer la concentration de testostérone du fait du rétrocontrôle de l'axe hypothalamo-hypophyso-testiculaire par la testostérone libre [17]. Ainsi le fait que l'obésité n'est pas un facteur protecteur du cancer de la prostate supporte l'idée que la testostérone circulante n'est pas un facteur de risque majeur de cancer de la prostate [17].

Pour que les concentrations d'androgènes circulants soient considérées comme importantes pour le développement du cancer de la prostate, elles doivent représenter un bon reflet de l'action intraprostatique des androgènes, mais ceci est mal connu. La signalisation intraprostatique des androgènes peut dépendre plus du taux de conversion par la $5 \alpha$ réductase-ll de la testostérone en dihydrotestostérone (DHT), l'androgène le plus puissant dans la prostate, et de la capacité d'activation du récepteur aux androgènes, que des niveaux circulants des androgènes $[4,20,16,10]$. Des polymorphismes affectant l'activité de la $5 \alpha$-réductase et le blocage pharmacologique de la réduction par la $5 \alpha$-réductase de la testostérone en DHT ont été associés avec un risque de cancer de la prostate dans certaines études [20, $16,26]$. II est important de noter qu'une très large étude randomisée a récemment démontré une réduction de $25 \%$ de la prévalence du cancer de la prostate chez les hommes traités par le finastéride en comparaison aux hommes trai- tés par un placebo [29]. De plus, le glucuronide d'androstanediol (A-diol-g), le principal métabolite circulant de la DHT, est le seul androgène significativement augmenté dans les cas de cancer de la prostate dans les méta-analyses [7]. Toutefois, les concentrations d'A-diol-g circulants ne reflètent que partiellement les niveaux de DHT intraprostatique, en effet, l'A-diol-g est aussi produit par la $5 \alpha$-réductase I de la peau. Enfin, la variation du nombre de répétitions du triplet CAG du récepteur aux androgènes qui affecte l'activité transcriptionnelle de l'ADN, peut aussi influencer le développement du cancer de la prostate $[10,21]$.

Une implication clinique de nos résultats concerne la supplémentation androgénique qui est devenue plus facile à administrer au moyen de gels ou de patches transdermiques [11, 32]. L'indication de supplémentation androgénique a été suggérée pour le traitement des hypogonadismes modérés et des effets bénéfiques ont été rapportés sur la dysfonction érectile, l'obésité abdominale, l'ostéoporose, la force musculaire et l'angine de poitrine [32, 22]. On s'inquiète de savoir si la supplémentation androgénique à un niveau de même importance que la production endogène de testostérone (3-10 $\mathrm{mg} / 24 \mathrm{~h}$ ) peut promouvoir un cancer de la prostate. Nos résuitats ne vont pas dans le sens de cette hypothèse. Néanmoins, comme les concentrations de SHBG sont légèrement diminuées par l'administration d'androgènes, les concentrations de testostérone libre augmentent proportionnellement plus que celle de testostérone totale [11] et ainsi, on ne sait pas si, du fait du contournement de la régulation normale de la production de testostérone, l'effet de l'apport constant de testostérone exogène peut être assimilé à l'effet de variations de la testostérone endogène à l'intérieur des valeurs physiologiques.

\section{CONCLUSION}

L'ensemble des résultats des études prospectives publiées sur les concentrations circulantes de testostérone totale et libre ne vont pas dans le sens de l'hypothèse que des niveaux élevés d'androgènes circulants sont associés avec un risque augmenté de cancer de la prostate $[7,17,27]$.

\section{REFERENCES}

1. ANDERSON D.C., THORNER M.O., FISHER R.A. et al. : Effects of hormonal treatment on plasma unbound androgen levels in hirsute women. Acta Endocrinol. Suppl. (Copenh), $1975,199: 224$.

2. BIANCHINI F., KAAKS R., VAINIO H. : Overweight, obesity, and cancer risk. Lancet Oncol., 2002, 3 : 565-574.

3. BLADOU F., VESSELA R.L., BUHLER K.R. et al. : Cell proliferation and apoptosis during prostatic tumor xenograft involution and regrowth after castration. Int. J. Cancer, 1996, 67 : 785790.

4. BOSLAND M.C. : The role of steroid hormones in prostate carcinogenesis. Journal of the National Cancer Institute Monographs, 2000, $27: 67-73$.

5. CALLE E.E., RODRIGUEZ C., WALKER-THURMOND $K$. et al.: Overweight, obesity, and mortality from cancer in a prospectively studied cohort of U.S. adults. N. Engl. J. Med., 2003, $348: 1625-1638$. 
6. DORGAN J.F., ALBANES D., VIRTAMO J. et al. : Relationships of serum androgens and estrogens to prostate cancer risk : results from a prospective study in Finland. Cancer Epidemiol. Biomarkers Prev., 1998, 7 : 1069-1074.

7. EATON N.E., REEVES G.K., APPLEBY P.N. et al. : Endogenous sex hormones and prostate cancer : a quantitative review of prospective studies. Br. J. Cancer, 1999, $80: 930-$ 934.

8. GANN P.H., HENNEKENS C.H., MA J. et al. : Prospective study of sex hormone levels and risk of prostate cancer. J. Natl. Cancer. Inst., 1996, 88 : 1118-1126.

9. GAPSTUR S.M., GANN P.H., KOPP P. et al. : Serum androgen concentrations in young men : a longitudinal analysis of associations with age, obesity, and race. The CARDIA male hormone study. Cancer Epidemiol. Biomarkers Prev., 2002, 11 : 1041-1047.

10. GIOVANNUCCI E., STAMPFER M.J., KRITHIVAS K. et al. : The CAG repeat within the androgen receptor gene and its relationship to prostate cancer. Proc. Natl. Acad. Sci. USA, 1997, 94 : 3320-3323.

11. GRUENEWALD D.A., MATSUMOTO A.M. : Testosterone supplementation therapy for older men : potential benefits and risks. J. Am. Geriatr. Soc., 2003, 51 : 101-115.

12. GUESS H.A., FRIEDMAN G.D., SADLER M.C. et al. : 5 alphareductase activity and prostate cancer : a case-control study using stored sera. Cancer Epidemiol. Biomarkers Prev., 1997, $6: 21-24$.

13. HEIKKILA R., AHO K., HELIOVAARA M. et al. : Serum testosterone and sex hormone-binding globulin concentrations and the risk of prostate carcinoma : a longitudinal study. Cancer, 1999, $86: 312-315$.

14. HSING A.W., COMSTOCK G.W. : Serological precursors of cancer : serum hormones and risk of subsequent prostate cancer. Cancer Epidemiol. Biomarkers Prev., 1993, 2 : 27-32.

15. HSING A.W., REICHARDT J.K., STANCZYK F.Z. : Hormones and prostate cancer: current perspectives and future directions. Prostate, 2002, $52:$ 213-235.

16. IRANI J., RAVERY V., PARIENTE J.L. et al. : Effect of nonsteroidal anti-inflammatory agents and finasteride on prostate cancer risk. J. Urol., 2002, 168 : 1985-1988.

17. KAAKS R., LUKANOVA A., SOMMERSBERG B. : Plasma androgens, IGF-I, body size and prostate cancer risk : a synthetic review. Prostate Cancer Prostatic. Dis., 2000, 3 : 157172.

18. KYPRIANOU N., ENGLISH H.F., ISAACS J.T. : Programmed cell death during regression of $\mathrm{PC}-82$ human prostate cancer following androgen ablation. Cancer Res., 1990, 50 : 37483753.

19. LUCIA M.S., BOSTWICK D.G., BOSLAND M. et al : Workgroup I : rodent models of prostate cancer. Prostate, 1998, $36: 49$ 55.

20. MAKRIDAKIS N.M., REICHARDT J.K. : Molecular epidemiology of hormone-metabolic loci in prostate cancer. Epidemiol. Rev., 2001, $23: 24-29$.

21. MONTGOMERY J.S., PRICE D.K., FIGG W.D. : The androgen receptor gene and its influence on the development and progression of prostate cancer. J. Pathol., 2001, 195 : 138-146.

22. MORALES A. : Androgen replacement therapy and prostate safety. Eur. Urol., 2002, $41: 113-120$.

23. MORLEY J.E., PATRICK P., PERRY H.M.3. : Evaluation of assays available to measure free testosterone. Metabolism, 2002, 51 : 554-559.

24. NAIR B., WILT.T., MACDONALD R. et al. : Early versus deferred androgen suppression in the treatment of advanced prostatic cancer. The Cochrane database of systematic reviews, 2002, Computer File 1: CD003506.

25. NOMURA A.M., STEMMERMANN G.N., CHYOU P.H. et al. : Serum androgens and prostate cancer. Cancer Epidemiol. Biomarkers Prev., 1996, 5 : 621-625.

26. NORMAN R.W., COAKES K.E., WRIGHT A.S. et al. : Androgen metabolism in men receiving finasteride before prostatectomy. J. Urol., 1993, $150:$ 1736-1739.

27. STATTIN P., LUMME S., TENKANEN L. et al. : High levels of circulating testosterone are not associated with increased prostate cancer risk : A pooled prospective study. Int. J. Cancer, 2004, $108: 418-424$.

28. SINNECKER G. : Stability of sex-hormone-binding globulin in serum and plasma. Clin. Chem., 1989, 35 : 1253-1254.

29. THOMPSON I.M., GOODMAN P.J., TANGEN C.M. et al. : The influence of finasteride on the development of prostate cancer. N. Engl. J. Med., 2003, $349:$ 215-224.

30. UKKOLA O., GAGNON J., RANKINEN T. et al. : Age, body mass index, race and other determinants of steroid hormone variability: the HERITAGE Family Study. Eur. J. Endocrinol., $2001,145: 1-9$.

31. VATTEN L.J., URSIN G., ROSS R.K. et al. : Androgens in serum and the risk of prostate cancer : a nested case-control study from the Janus serum bank in Norway. Cancer Epidemiol. Biomarkers Prev., 1997, 6 : 967-969.

32. VERMEULEN A. : Androgen replacement therapy in the aging male-a critical evaluation. J. Clin. Endocrinol. Metab., 2001, $86: 2380-2390$.

33. VERMEULEN A., VERDONCK G. : Representativeness of a single point plasma testosterone level for the long term hormonal milieu in men. J. Clin. Endocrinol. Metab., 1992, 74 : 939942.

34. VERMEULEN A., VERDONCK L., KAUFMAN J.M. : A critical evaluation of simple methods for the estimation of free testosterone in serum. J. Clin. Endocrinol. Metab. 1999, 84 : 36663672 .

35. WEBBER M.M., BELLO D., QUADER S. : immortalized and tumorigenic adult human prostatic epithelial cell lines : characteristics and applications. Part I. Cell markers and immortalized nontumorigenic cell lines. Prostate, 1996, 29 : 386-394.

Communication au $X X^{\circ}$ Congrès de la Société d'Andrologie de Langue Française,

Ortéans, 11-13 Décembre 2003.

Manuscrit reçu : février 2004 ; accepté mars 2004. 


\section{ABSTRACT}

Circulating testosterone and prostate cancer. A brief review

\section{Pär STATTIN}

In vitro and in vivo studies show that androgens stimulate prostate cancer. However, evidence from epidemiological studies of an association between circulating levels of androgens and prostate cancer risk has been inconsistent, but most studies have likely been undersized given that the association may be relatively weak.

We review prospective studies on the association of serum levels of free and total testosterone, the principal androgen in circulation with risk of prostate cancer.

No significant association between total or free testosterone and risk of prostate cancer was found in studies that together included 1,525 cases of prostate cancer and 4,349 controls.

No support was found for the hypothesis that high levels of circulating testosterone within a physiological range stimulate development and growth of prostate cancer. Intraprostatic androgen metabolism may still be of importance for prostate cancer development.

Key words : prostate cancer, androgens, testosterone, epidemiology, prospective studies 